INTRODUCTION TO NON-LINEAR OPTIMIZATION 


\section{Macmillan Computer Science Series}

Consulting Editor

Professor F. H. Sumner, University of Manchester

S.T. Allworth, Introduction to Read-time Software Design

Ian O. Angell, A Practical Introduction to Computer Graphics

G.M. Birtwistle, Discrete Event Modelling on Simula

T.B. Boffey, Graph Theory in Operations Research

Richard Bornat, Understanding and Writing Compilers

J.K. Buckle, The ICL 2900 Series

J.K. Buckle, Software Configuration Management

J.C. Cluley, Interfacing to Microprocessors

Robert Cole, Computer Communications

Derek Coleman, A Structural Programming Approach to Data*

Andrew J.T. Colin, Fundamentals of Computer Science

Andrew J.T. Colin, Programming and Problem-solving in Algol 68*

S.M. Deen, Fundamentals of Data Base Systems*

P.M. Dew and K.R. James, Introduction to Numerical Computation in Pascal

K.C.E. Gee, Introduction to Local Area Computer Networks

J.B. Gosling, Design of Arithmetic Units for Digital Computers

David Hopkin and Barbara Moss, Automata*

Roger Hutty, Fortran for Students

Roger Hutty, Z80 Assembly Language Programming for Students

Roland N. Ibbett, The Architecture of High Performance Computers

H. Kopetz, Software Reliability

E.V. Krishnamurthy, Introductory Theory of Computer Science

Graham Lee, From Hardware to Software: an introduction to computers

A.M. Lister, Fundamentals of Operating Systems, second edition*

G.P. McKeown and V.J. Rayward-Smith, Mathematics for Computing

Brian Meek, Fortran, PL/1 and the Algols

Derrick Morris, An Introduction to System Programming - Based on the PDP11

Derrick Morris and Roland N. Ibbett, The MU5 Computer System

John Race, Case Studies in Systems Analysis

L.E. Scales, Introduction to Non-Linear Optimization

Colin J. Theaker and Graham R. Brookes, A Practical Course on Operating Systems

B.S. Walker, Understanding Microprocessors

Peter J.L. Wallis, Portable Programming

I.R. Wilson and A.M. Addyman, A Practical Introduction to Pascal - with BS

6192, second edition

*The titles marked with an asterisk were prepared during the Consulting Editorship of

Professor J.S. Rohl, University of Western Australia. 


\title{
Introduction to Non-Linear Optimization
}

\author{
L.E. Scales
}

Department of Computer Science

University of Liverpool

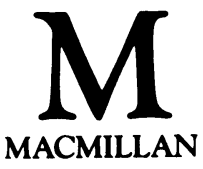


ㄷ L. E. Scales 1985

All rights reserved. No part of this publication may be reproduced or transmitted, in any form or by any means, without permission.

First published 1985 by

Higher and Further Education Division

MACMILLAN PUBLISHERS LTD

London and Basingstoke

Companies and representatives

throughout the world

Typeset in Great Britain by

RDL Artset Ltd, Sutton, Surrey

British Cataloguing in Publication Data

Scales, L. E.

Introduction to non-linear optimization.

(Macmillan computer science series)

1. Mathematical optimization

2. Nonlinear theories

I. Title

$515 \quad$ QA402.5

ISBN 978-0-333-32553-7

DOI 10.1007/978-1-349-17741-7 


\section{Contents}

Preface 1

$\begin{array}{ll}\text { INTRODUCTION } & 7\end{array}$

1. FUNDAMENTALS OF UNCONSTRAINED OPTIMIZATION

1.1 Introduction 7

$\begin{array}{lll}\text { 1.1.1 Vectors, functions and derivatives } & 7\end{array}$

1.1.2 Types of unconstrained minimum 9

1.2 Necessary and Sufficient Conditions for an Unconstrained Minimum 14

$\begin{array}{lll}\text { 1.2.1 The first-order condition } & 14\end{array}$

1.2.2 Second-order conditions 15

1.3 Quadratic Functions 16

1.3.1 Derivatives of quadratic functions 16

$\begin{array}{ll}\text { 1.3.2 Types of quadratic function } & 17\end{array}$

1.3.3 The eigensystem of the Hessian matrix 19

1.4 The Convergence of Minimization Algorithms 23

1.4.1 Stability 23

1.4.2 Rate of convergence 24

1.5 Summary 25

2. UNIVARIATE MINIMIZATION 26

2.1 Introduction 26

2.1.1 Linear search and univariate minimization 26

2.2 Function Comparison Methods 27

2.2.1 Basic principles 28

2.2.2 Fibonacci search $\quad 30$

2.2.3 Golden Section search 31

2.2.4 Bisection 34

2.3 Polynomial Interpolation Methods 35

2.3.1 Quadratic interpolation 36

2.3.2 Cubic interpolation 38

2.4 Interval Location 41

2.4.1 Function comparison methods 41

2.4.2 Polynomial extrapolation methods 41

2.5 Hybrid Methods 46

2.5.1 Combined quadratic approximation and Golden Section $\quad 46$

2.5.2 Combined cubic approximation and bisection $\quad 50$ 
2.6 Aspects of Univariate Minimization Specific to Linear Search 51

$\begin{array}{ll}\text { 2.6.1 Use of derivatives in linear search } & 51\end{array}$

2.6.2 Termination criteria for inaccurate linear search $\quad 53$

2.7 Summary $\quad 55$

3. MULTIVARIATE MINIMIZATION 56

3.1 Introduction $\quad 56$

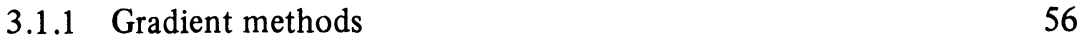

3.1.2 Descent directions and directions of negative curvature $\quad 57$

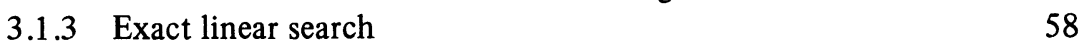

3.1.4 Finite difference techniques $\quad 58$

3.2 The Method of Steepest Descent 59

$\begin{array}{ll}3.2 .1 \text { Convergence } & 60\end{array}$

3.3 Modified Newton Methods $\quad 61$

$\begin{array}{ll}\text { 3.3.1 Newton's method } & 62\end{array}$

3.3.2 Convergence of Newton's method 63

3.3.3 Using the eigensystem of the Hessian matrix 64

3.3.4 Using the Cholesky factorization of the Hessian matrix 65

$\begin{array}{lll}3.3 .5 & \text { Saddle points } & 66\end{array}$

3.3.6 Sparsity in the Hessian matrix 68

3.3.7 The performance of modified Newton methods 69

$\begin{array}{ll}3.4 \text { Conjugate Gradient Methods } & 73\end{array}$

$\begin{array}{ll}\text { 3.4.1 Conjugacy and linear independence } & 74\end{array}$

$\begin{array}{ll}\text { 3.4.2 Quadratic termination } & 75\end{array}$

3.4.3 The construction of conjugate search vectors 76

3.4.4 Conjugate gradient methods for non-quadratic functions $\quad 79$

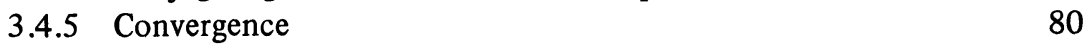

$\begin{array}{lll}\text { 3.4.6 Projection matrices } & 81\end{array}$

3.4.7 The derivation of particular conjugate gradient methods $\quad 81$

$\begin{array}{lll}\text { 3.4.8 Partial conjugate gradient methods } & 82\end{array}$

3.4.9 The performance of conjugate gradient methods $\quad 83$

$\begin{array}{ll}\text { 3.5 Quasi-Newton Methods } & 84\end{array}$

3.5.1 The David-Fletcher-Powell formula 85

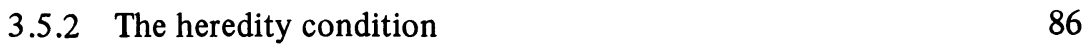

$\begin{array}{ll}\text { 3.5.3 Huang's family of updating formulae } & 87\end{array}$

3.5.4 Broyden's family of updating formulae 88

3.5.5 B-matrix formulation of quasi-Newton methods 90

$\begin{array}{ll}\text { 3.5.6 Positive definiteness in Broyden's family } & 92\end{array}$

3.5.7 Conjugacy and the heredity property in Broyden's family 94

3.5.8 The choice of parameter in Broyden's family 95

3.5.9 The convergence of rank-one methods 96

3.5.10 The convergence of rank-two methods 97

3.5.11 The implementation of numerically stable quasi-Newton
methods 
3.5.12 Updating Cholesky factors

3.5.13 Methods using finite difference techniques

3.5.14 Optimal conditioning, self-scaling, sparsity and other topics 101

3.5.15 The performance of quasi-Newton methods 103

3.6 Summary

4. NON-LINEAR LEAST SQUARES

4.1 Introduction 110

4.1.1 Non-linear regression $\quad 110$

4.1.2 Simultaneous non-linear equations 111

$\begin{array}{ll}\text { 4.1.3 Derivatives of sum-of-squares functions } & 112\end{array}$

4.1.4 Newton's method 113

4.2 Small Residual Algorithms 113

4.2.1 The Gauss-Newton method 114

4.2.2 The Levenberg-Marquardt method 115

4.2.3 Powell's hybrid method 118

$\begin{array}{ll}\text { 4.2.4 Solution of the normal equations } & 121\end{array}$

4.2.5 Finite difference techniques 124

4.2.6 Quasi-Newton methods 125

$\begin{array}{ll}\text { 4.2.7 Simultaneous non-linear equations } & 127\end{array}$

4.3 Large Residual Algorithms 130

4.3.1 Quasi-Newton methods 130

4.3.2 The Gill-Murray method 132

4.3.3 Hybrid and general minimization methods $\quad 136$

4.4 Summary 136

5. FUNDAMENTALS OF CONSTRAINED OPTIMIZATION 139

5.1 Introduction 139

5.1.1 Some notation and basic concepts 139

5.2 Necessary and Sufficient Conditions for a Linearly Constrained

Minimum $\quad 142$

5.2.1 Definition of a linearly constrained minimum 142

5.2.2 First-order necessary condition for equality constraints 142

5.2.3 Second-order conditions for equality constraints 144

5.2.4 First-order necessary condition for inequality constraints $\quad 146$

5.2.5 Second-order conditions for inequality constraints 146

5.3 Necessary and Sufficient Conditions for a Non-linearly

Constrained Minimum

5.3.1 Definition of a non-linearly constrained minimum 147

5.3.2 First-order necessary conditions for equality and inequality constraints

5.3.3 Second-order conditions for equality and inequality constraints 
6.1 Introduction

6.1.1 Active set strategy

6.1.2 Lagrange multiplier estimates

6.1.3 Updating after a change of basis 156

6.2 Modified Newton Methods 159

6.2.1 Newton's method 159

6.2.2 The Gill-Murray modified Newton method 160

$\begin{array}{ll}6.3 \text { Quasi-Newton Methods } & 165\end{array}$

6.3.1 H-matrix formulation $\quad 165$

$\begin{array}{ll}\text { 6.3.2 B-matrix formulation } & 169\end{array}$

6.4 Determination of a Feasible Initial Point 174

$\begin{array}{ll}\text { 6.4.1 Equality constraints } & 174\end{array}$

\begin{tabular}{ll}
6.4 .2 & Inequality constraints \\
\hline
\end{tabular}

$\begin{array}{lll}6.5 \text { Summary } & 177\end{array}$

7. NON-LINEARLY CONSTRAINED MINIMIZATION 179

$\begin{array}{ll}7.1 \text { Introduction } & 179\end{array}$

$\begin{array}{ll}\text { 7.2 Penalty and Barrier Function Methods } & 180\end{array}$

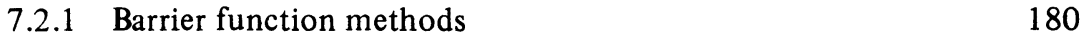

7.2.2 Simple penalty function methods 184

$\begin{array}{ll}\text { 7.2.3 Powell's penalty function } & 189\end{array}$

$\begin{array}{ll}7.3 \text { Augmented Lagrangian Methods } & 194\end{array}$

$\begin{array}{ll}\text { 7.3.1 Exact augmented Lagrangian methods for equality } & 195\end{array}$

7.3.2 Exact augmented Lagrangian methods for inequality 203 constraints 203

7.3.3 Sequential augmented Lagrangian methods for equality
constraints

7.3.4 Sequential augmented Lagrangian methods for inequality constraints

$\begin{array}{lll}\text { 7.4.1 } & \text { Direct projection methods for equality constraints } & 215 \\ \text { 7.4.2 } & \text { Direct projection methods for inequality constraints } & 218\end{array}$

$\begin{array}{ll}7.5 \text { Projected Lagrangian Methods } & 222\end{array}$

7.5.1 Projected Lagrangian methods for equality constraints 222

7.5.2 Projected Lagrangian methods for inequality constraints 228

$\begin{array}{lll}7.6 \text { Summary } & 228\end{array}$

$\begin{array}{ll}\text { References } & 232\end{array}$

$\begin{array}{lr}\text { Index } & 240\end{array}$ 


\section{Preface}

There are many books on non-linear optimization, so why another? A large part of the answer lies with the tremendous rate of growth in knowledge about problemsolving methods in this subject in recent times. At the time of writing, it is the 21 st anniversary of the publication of the seminal paper by Fletcher and Powell (1963) which first made widely accessible the innovations of Davidon (1959). This is a turning point in the history of non-linear optimization methods and can be taken as marking the start of the modern exponential growth in research, software development and applications, all feeding off one another. It was then possible for the first time to locate the minimum of a smooth non-linear function efficiently without knowledge of second derivatives and with relatively little risk of going astray in the process. All that was needed was a computer with a sufficiently large memory. In the following year, even this restriction was relaxed (with some reservations) in the work of Fletcher and Reeves (1964), another milestone on the way. The next few years saw work upon improving the reliability of Newton's method and the fuse was lit for the explosion that followed.

The solution of linear optimization problems had been substantially understood at this time for almost two decades. These methods had been widely applied and they still are. However, one is always looking for better models of the real world and increasingly these have tended to become non-linear. In this way motivation has constantly been provided for the development of improved methods. The 1970s saw software development becoming a science (or perhaps a branch of engineering?) in itself, and reliable implementations, by no means easily achieved, of the better methods gradually appeared in an orderly, well-documented manner as, for example, in the NAG library. This has increasingly removed the burden of programming from the user to the expert. The reader will have noticed that we are talking about non-linear optimization methods. The theory of non-linear optimization dealing with constrained and unconstrained maxima and minima is an important branch of mathematics that had been long understood, but which can still provide difficulties for those in the practice of optimization who are not primarily mathematicians. The emphasis of this book is upon methods.

What is the situation in 1984? The growth continues unabated. The published literature compares in quantity with a well-known encyclopaedia of many volumes. New methods appear regularly, as do significant refinements of existing methods and enhancements of our theoretical understanding. So what hope is there of writing a book that will not be out of date almost as soon as it appears? Well, fortunately a backbone of methods covering almost all of the subject, and sup- 
ported by comprehensive theory and widely available reliable implementations, has come into focus. These methods will not readily be superseded in practice for some time yet and the potential user will benefit from their study. In support of the worthiness of such a study is the observation that the growth in non-linear optimization over the last two decades has been evolutionary rather than revolutionary.

This is a book primarily about the main core of quite generally applicable nonlinear optimization methods. The reader will also notice that some of the methods discussed have, or should have, passed out of use, but will find that these methods have a more than historical influence on the subject. A considerable unity within the field has emerged over the last decade or so. The author has had to be selective in the material discussed, but this has been done with a mind to emphasise unity and generality of application. Some old favourites (largely obsolete) do not appear. On the other hand, some obsolete methods nicely complete the picture and are included for this reason, although a related effect is that they generally provide some motivation for the better methods. The theory of minima is covered informally and in general the level of mathematical rigour is not very high; arguments often suggest results rather than prove them. This is therefore a book for actual or potential practising optimizers who need to know how methods work, how to select methods for the job in hand and how to use the chosen method. However, it is a mathematical subject and the reader must expect to see a considerable amount of mathematical argument on these pages. On the whole, the level is that usually covered in mathematics courses in numerate disciplines like physical science, engineering and computational mathematics by the end of the second year at university. More advanced topics are discussed briefly where relevant in the text. The main emphasis is upon linear algebra, which permeates the subject, and to a lesser extent upon multivariable calculus. Many standard texts are available that cover this material. The author finds particularly useful for reference the books by Stewart (1973) and Lancaster (1969) (linear algebra) and by Apostol (1957) (calculus).

The author's interest in non-linear optimization stems from advisory support to users at Liverpool University, from various projects in connection with the NAG library and from teaching. This book developed out of notes for a course of twenty lectures given to final year honours students taking degrees mainly in some form of computational mathematics. The project has grown, and it is feasible to cover only rather less than half of the material now presented in such a course. It is hoped that the full text will satisfy many of the requirements of research workers and optimization users in universities and industry.

I am indebted to many for assistance of one sort or another in the preparation of this book. In particular I should like to mention Shirley Hancock (once known in the optimization world as Shirley Lill) who suggested I should write the book when she finally came to terms with the fact that she would never get round to it herself; Dr. Brian Sutcliffe, a great mind and inspiration from my student days, who read a large chunk of the manuscript and provided detailed comment and boundless enthusiasm when it was badly needed; Professor Jim Alty, boss and friend, who 
proposed 9 months of sabbatical leave for me, and the University of Liverpool who granted it; the operators at the University of Liverpool Computer Laboratory, who finally coaxed perfect figures from an unhelpful graph plotter; J.S. Bach and his contemporaries, who cleared my mind when it became too congested; and my wife, Joan, who many times persuaded me back to work on the manuscript when I looked like abandoning it for other things.

Liverpool, 1984

L.E. SCALES 